\title{
Assessment of Cytokeratin Expression in Carcinoma Breast
}

\author{
Preeti Mishra ${ }^{1}$, Sunita Vagha², Samarth Shukla ${ }^{3}$, Sourya Acharya ${ }^{4}$, Aditi Goyal ${ }^{5}$ \\ 1Department of Pathology, Jawaharlal Nehru Medical College, DMIMSU, Sawangi (Meghe) Wardha, \\ Maharashtra, India. ${ }^{2}$ Department of Pathology, Jawaharlal Nehru Medical College, DMIMSU, Sawangi \\ (Meghe) Wardha, Maharashtra, India. ${ }^{3}$ Department of Pathology, Jawaharlal Nehru Medical College, \\ DMIMSU, Sawangi (Meghe) Wardha, Maharashtra, India. ${ }^{4}$ Department of Medicine, Jawaharlal Nehru \\ Medical College, DMIMSU, Sawangi (Meghe) Wardha, Maharashtra, India. ${ }^{5}$ Department of Pathology, \\ Jawaharlal Nehru Medical College, DMIMSU, Sawangi (Meghe) Wardha, Maharashtra, India.
}

\section{ABSTRACT}

\section{BACKGROUND}

Breast cancer is the most common malignancy in females and an important cause of cancer deaths worldwide. With advances in oncopathology, breast cancers are now diagnosed and treated at a molecular level. To distinguish and subdivide the type of cancer with the suitable markers and to foresee its prognosis and therapeutic approach, cytokeratin can be used which is prognostic tumour marker and has a number of different advantages as it is an important IHC marker, cytokeratin (Ck) is epithelial intermediate filament, which is expressed in a tissue specific manner. Expression of the intermediate filaments, predominantly cytokeratins (Ck) reflects the epithelial cell type. In breast, the luminal epithelial cells express CK 8 / 18, CK 7 and CK 19, while basal cell expresses CK 5 / 6, CK 14 and CK 17. Bloom Richardson grading (BR) system has a powerful prognostic value. It is also incorporated in the algorithm for the determination in the use of adjuvant chemotherapy. Moreover, as a tumour marker cytokeratin can accurately predict disease status as it is easy, inexpensive and a reliable tool for efficient management. CK and BR grading can be used as cost effective diagnostic tools in hormone positive breast carcinoma for diagnosis as well as treatment. Very early detection of breast cancer reduces the mortality and morbidity.

\section{KEY WORDS}

Breast Carcinoma, Cytokeratins, BR Grading
Corresponding Author: Ms. Preeti Mishra, Department of Pathology, Jawaharlal Nehru Medical College, DMIMSU, Sawangi (Meghe) Wardha, Maharashtra, India. E-mail: preeti1707mishra@gmail.com

DOI: $10.14260 / \mathrm{jemds} / 2020 / 553$

How to Cite This Article:

Mishra P, Vagha S, Shukla $S$, et al. Assessment of cytokeratin expression in carcinoma breast. J Evolution Med Dent Sci 2020;9(35):2545-2549, DOI: $10.14260 /$ jemds $/ 2020 / 553$

Submission 05-05-2020,

Peer Review 15-07-2020,

Acceptance 22-07-2020,

Published 31-08-2020.

Copyright (C) 2020 JEMDS. This is an open access article distributed under Creative Commons Attribution License [Attribution 4.0 International (CC BY 4.0)] 


\section{BACKGROUND}

Breasts are highly modified apocrine sweat glands which develop embryologically along 2 milk lines which extends from the axilla to groin. The breast of both sexes follow a similar course of development until puberty after which female breast develops under influence of pituitary, ovarian and other hormones.(1)

Breast is a common site for pathological lesions like cyst, sclerosing adenosis, small duct papilloma, duct ectasia, adenoma, Paget's disease, carcinoma etc. Carcinoma Breast is the commonest non-skin malignancy among females and ranks $2^{\text {nd }}$ to lung cancer as an important reason of cancer deaths.(2)

\section{Epidemiology}

Breast cancer is the commonest female cancer worldwide representing 20,88,849 new cases of cancer and 6,26,679 deaths from cancer in 2018. GLOBOCAN 2018 estimation, India along with US and China accounts for 1 / 3rd of global cancer burden.(3)

\section{Predisposing Factor}

Various risk factors of carcinoma breast are - germ line mutation, $1^{\text {st }}$ degree relatives of breast cancer, race and ethnicity, age around 70 - 80 years, age at menarche (younger age less than 11 years increases the risk by $20 \%$ ) and late age first live birth, benign breast disease, increased oestrogen exposure, breast density, increased radiation exposure, carcinoma of contralateral breast, diet, obesity, lack of exercise, lack of breast feeding and environmental toxins.(2)

Prognostic factors of carcinoma breast like age less than 35 years of age have poor prognosis, another important prognostic factor is stage for breast cancer that is if it is diagnosed at a late stage which includes increased risk of recurrence, so it has less favourable outcome; some other factors includes spread to lymph node if it spreads to four or more LN it has higher risk for recurrence, size of tumour will also affect the breast cancer outcome, low grade tumour have relatively good prognosis; hormone receptor status have better prognosis. Prognostic factor depends upon the grade of the patient. The grading system which is most commonly used is Bloom Richardson Grading (Scharf-Bloom-Richardson Grading System) has a potent predictive value. It is also incorporated in algorithm to determine the use of adjuvant chemotherapy. Moreover it is easy and cheap. ${ }^{(4)}$

The predisposing factors play an essential role and every health professional should make the women aware of the same, so that they can be diagnosed early and thus treated early resulting in a better prognosis.

\section{Grading of Breast Cancer}

Grading of the tumour shows potential malignancy and is valuable as it gives the probable extent of a tumour and survival rates. A sign of the degree of malignancy in breast cancer is obtained by means of a histological grading system which has undergone regular revision by Greenough in 1925, Patey and Scarff in 1928, Haagensen in 1933 and finally by
Bloom in 1950. For grading breast cancer epithelial elements are used.(5)

Over the past few years, there are different scoring system for determining the grade of breast cancer that is Nottingham Histologic Score System. This score depends upon amount of gland formation, degree of nuclear pleomorphism and the mitotic activity.

Each of these are scored from 1 - 3, then the scores are added and to give a final score which ranges from 3 - 9. This final score is used to determine the grade.

- $\quad$ Score 3, 4, 5 - Grade I (Low Grade)

- Score 6, 7 - Grade II (Intermediate Grade)

- $\quad$ Score 8, 9 - Grade III (High Grade)

Survival for patients with grade I carcinoma which gradually declines to seventy percent at twenty four years of age. Most deaths for grade III carcinomas occur in the $1^{\text {st }}$ ten years, and forty five percent of patients survive for long-term duration. Female with grade II carcinomas have better survival initially, but their long-term survival is slightly better than grade III cancers. $\left.{ }^{5}, 6\right)$

Immunophenotype of Breast by St. Gallen's Classification Breast carcinoma is a heterogeneous disease with several clinical and histopathological presentations, which present different gene expressions in several subtypes and molecular profiles, hence giving different predictive and prognostic characteristics for the patients. ${ }^{(7)}$

According to 12th International St. Gallen Breast Cancer Conference in March 2011, 5 subtypes of breast cancer were defined using IHC to analyse the expression of four markers ER, PR, HER2, and Ki-67. This clinicopathological subtyping of breast cancer represents a similar but more practical approach than molecular typing. ${ }^{(8)}$

Gene expression profile, measures the quantity of mRNA for every gene, identified 5 patterns of gene expression and these are luminal A, luminal B, basal-like, and HER2 positive. These molecular classes correlate with the prognosis and response to therapy.

\begin{tabular}{|c|c|c|c|}
\hline $\begin{array}{l}\text { Subtypes of Breast } \\
\text { Cancer }\end{array}$ & ER and PR & HER 2 neu & Ki67 \\
\hline Luminal A & $\mathrm{ER}+$ and or PR - & HER 2 negative & Ki $67<14 \%$ \\
\hline $\begin{array}{l}\text { Luminal B with HER } 2 \\
\text { Negative }\end{array}$ & $\mathrm{ER}+$ and or $\mathrm{PR}$ - & HER 2 negative & Ki $67>14 \%$ \\
\hline $\begin{array}{c}\text { Luminal B with HER } 2 \\
\text { Positive }\end{array}$ & $\mathrm{ER}+$ and or $\mathrm{PR}+$ & HER 2 positive & Any Ki67 \\
\hline HER 2 Enriched & ER - , PR - & HER 2 positive & Any Ki67 \\
\hline Basal Type & ER - , PR - & HER 2 negative & $\begin{array}{c}\text { CK5 / } 6+\text { and / or } \\
\text { EGFR }+\end{array}$ \\
\hline \multicolumn{4}{|c|}{ Table 1. Breast Immunophenotypes ${ }^{(9)}$} \\
\hline
\end{tabular}

\section{Luminal A}

Hormone Receptor positive (ER / PR positive), HER 2 neu negative and low levels of Ki 67. ER-positive carcinomas show increased transcription of genes which are characteristic of normal luminal cells. They occur in postmenopausal women. These cancers are slow growing and they respond to hormonal treatments. 


\section{Luminal B}

Hormone receptor positive (ER / PR positive) and either HER 2 positive or HER 2 negative with high levels of Ki 67 . They are also called as triple-positive cancers.

\section{Triple Negative / Basal Like}

Hormone receptor negative (ER / PR negative) and HER 2 neu negative. Basal-like cancers are important because of their genetic and epidemiologic features.

\section{HER 2 Enriched}

Hormone receptor negative (ER / PR negative) and HER 2 positive. HER 2 enriched cancers tend to grow faster than, luminal cancers and have worst prognosis. $(2,10)$ Knowing the subtype of breast cancer, in addition to the histological type and TNM stage, can suggest further prognosis of the disease, detect the spreading and find where metastases can appear later, but can also suggest further therapeutic approach.(11)

\section{Immunohistochemistry in Breast Carcinoma}

With the beginning of IHC, it has become a standard tool for diagnosis and prognosis of tumours. It is used to characterize intracellular proteins, or various cell surfaces in all tissues. The main diagnostic problem that arise in breast are different types of carcinoma, immunohistochemistry can be used to identify histologic subtype or molecular phenotype as mentioned above. Single IHC markers can be used to characterize different tumour subtypes, confirms the tissue of origin, differentiate metastatic from primary tumour and give additional information for prognosis, predicting response to therapy or for the evaluation of residual tumour post treatment.(12) Normal glandular tissue composed of 3 cell types that expresses different subsets of proteins that is luminal, basal, and myoepithelial. The luminal type expresses CK 7, 18, 19, EMA, milk fat globules, ER, PR.(13) Immunohistochemistry markers that takes part in the diagnosis of breast cancer are ER, PR, HER2, Ki67, p53, cyclin D1, cyclin Dib, cyclin E1, BRCA1 / 2, cytokeratins.(14)

\section{What are Cytokeratins?}

(CK) is an intermediate filament protein, which expresses in a tissue-specific manner. 2 types of Cytokeratins: Type I and Type II.(15) There are 20 different types of Cytokeratins: CK 1 to 20 . CK 9 to CK 20 are known as type I CKs, whereas CK 1 to CK 8 are called as type II CKs. Cytokeratin 5 and Cytokeratin 14 are expressed in myoepithelial cells of normal breast whereas CK 7, 8, 18 and 19 are expressed in the ductal epithelium. CK profile of the cell is retained during the course of genesis of malignancy.(16) This character of the Cytokeratin increases its prognostic and therapeutic value as it maintains its standard through the course of malignancy. Basal cytokeratins represents high molecular weight (HMW) cytokeratins which are seen in the basal cell layers. These cytokeratins are also expressed in the basally-located myoepithelial cell layer.(17) $\mathrm{CK} 18$, is a type I intermediate filament protein, and its co-expressed with type II partner, CK 8 are expressed in a various adult epithelial organs including breast and are also expressed by cancers that arise from these tissues.(18)

\section{Expression of Various Types of Cytokeratins}

CK 8 and its partner CK 18 are primary keratin pair in various simple epithelial cells like hepatocytes, pancreatic cells and they are also found in respiratory, glandular epithelium and in urothelium also. CK 7 and CK 19 expressed in simple epithelial cells. CK 20 is expressed in GIT epithelia, the urothelium and in skin. CK 5 and CK 14 form the main keratin pair in keratinocytes of stratified squamous epithelia. CK 6 and CK 16 have been identified in the epidermis. CK 17 is a myoepithelial cell keratin that is characteristically induced after skin injury.(19)

\section{Utility of Cytokeratins in Breast Cancer}

IHC assessment of members Cytokeratin family have been used since a decade for the histopathological examination of breast carcinoma. It has been well established that the highest sensitivity in identification of breast carcinoma is seen with $\mathrm{CK}$ 7, CK 8, CK 18 and CK 19. Cytokeratin 7 and Cytokeratin 8 is found beneficial in identification of breast cancer, even when the cells are present in very small numbers.(16) Breast adenocarcinomas, including ductal and lobular subtypes, mainly express CK 7, 8, 18 and 19. CK 8 exhibits a predominantly peripheral staining pattern in ductal carcinoma as compared to a ring-like, perinuclear pattern in lobular carcinoma.(20) CK 5 / 6, CK 14 and CK 17, are also expressed in breast cancer.(21) It is established that the luminal cells are formed after the basal cells and their formation is the evidence of the resemblance of luminal cell type with normal breast type suggests that there is inadequate tubule formation thus proposing invasion of tumour cells.(22)

\section{i. Correlation of Cytokeratin with Grades of Breast Carcinoma}

Study done by Dalia M Abd-El-Rahim et al, 1944 cases of invasive cancers of Breast were associated and the clinicopathological parameters showed positive correlation with basal markers.(23) Alshareeda conducted a study on 995 cases of breast cancer and used four basal cytokeratin markers (CK 5, CK 5 / 6, CK 14 and CK 17) and aimed to study the association between basal cytokeratin expression and the development of aggressive characteristics of the tumour. Positivity of each of the basal $\mathrm{Ck}$ was associated with higher BR grade, increased mitosis, increased pleomorphism, lack of tubule formation and tumour size $>1.5 \mathrm{~cm}$ showing poor outcome. Many studies have identified that the loss of luminal cytokeratins are associated with poor prognosis and similar outcomes with the presence of basal cytokeratins. $(24,25,26)$

Therefore, we want to glorify the fact that most studies want to frame a correlation of expression of luminal cytokeratins with better prognosis having a lesser BR grade, and, poor outcomes with a higher histological grade in cases with basal cytokeratin positivity. 


\section{ii. Relevance of Cytokeratin in Predicting Breast Immunophenotypes}

In a study done by Laakso et al, 288 breast cancer cases were selected for studying the cytokeratin positivity. All tumour masses showed positivity for CK 5 / 14; thus, to learn the luminal CK pattern, CK 8, 18 and 19 immunostaining was done separately. These tumours expresses both basal and luminal CKs simultaneously and thus may originate from luminal progenitor cells of the breast.(27) Another by Schaller et al, showed that the expression of luminal marker was associated with good outcome, in contrast to the expression of basal markers, which was associated with poor prognostic features and behaviour.(28) CK 5 / 6 is the basal marker and CK 8 / 18 is the luminal marker of breast cancer and have pathological and prognostic significance in breast cancer. In some other research study it was proposed that CK 5 / 6 is marker of shorter disease free survival.(29) Aiad et al. conducted a study involving seventy breast cancer cases, found abnormal expression of CK 8 / 18 in $70 \%$ cases of breast cancer, which suggest a lot of heterogeneity in CK expression of breast cancer in different parts of world. Some researchers have proposed that loss of CK 8 / 18 expression / low CK 8 / 18 is associated with worse prognosis. (30)

Though there are few variations in the results of all the studies over the last decade about cytokeratin expression, we shouldn't debate on its relevance with the breast immunophenotypes. The luminal cytokeratins have shown positivity in Luminal A and Luminal B phenotypes while the basal cytokeratins have been expressed in HER-2 new enriched and basal types.

The present study was undertaken to analyse and assess the correlation between The Nottingham Modification of Bloom-Richardson Grading System with the immunophenotypes of breast tumour tissue, and also finds an important need to establish a relation between the cytokeratin positivity and each of the immunophenotypes.

\section{Utility of Cytokeratins in Other Carcinomas}

Adenocarcinomas expresses CK 8, 18 and 19 whereas CK 7 and CK 20 expression is inconsistent. Cytokeratin typing provides important diagnostic significance in case of colorectal adenocarcinoma. Pancreatic and oesophageal tissue evenly express CK 7, 20 expresses.(31) Whereas a CK 7 positivity / CK 20 negativity phenotype is characteristic of ovarian, endometrial cancer.(19)

\section{CONCLUSIONS}

Blending the histopathologic grades with cytokeratin positivity in breast cancer tissue has been of value for prognostication instead of using other expensive markers. Cytokeratin along with Bloom Richardson grading can be used as a diagnostic and prognostic tool as it is cost effective. It can also be used to predict the immunophenotype profile of breast cancers.

The review identifies the fact that basic immunophenotypes have an excellent correlation with the cytokeratin status along with the Bloom-Richardson Grading System. The centers in the pastoral parts of the country find it difficult to achieve patient compliance because of the exorbitant expense of the cocktail of immunohistochemical markers advised by clinicians. So, cytokeratins can be used because the cytokeratin status by itself can possibly differentiate breast cancer into low grade (Luminal $\mathrm{A}$ and Luminal B type) and high grade (HER-2 enriched and triple negative). It can be considered as a reliable alternative tool along with BR grading, for the prediction of endocrine status of breast cancer cases in rural parts of the globe, in particular, where accessibility and affordability is difficult to achieve.

Financial or Other Competing Interests: All authors received grants from Jawaharlal Nehru Medical College Sawangi (M) Wardha , during the conduct of the study;

\section{REFERENCES}

[1] Young B, O'Dowd G, Woodford P. Female reproductive system. In: Wheater's functional histology: a text and color atlas. $6^{\text {th }}$ edn. Philadelphia, PA: Churchill Livingston/Elsevier 2014: p. 378.

[2] Kumar V, Abbas AK, Aster JC. The Breast. In: Robbins and cotran pathology basis of disease south Asian edition. Vol. 2. Elsevier India 2014: p. 1046,1051-4, 7.

[3] Bray F, Ferlay J, Soerjomataram I, et al. Global cancer statistics 2018: GLOBOCAN estimates of incidence and mortality worldwide for 36 cancers in 185 countries. CA: Cancer J Clin 2018;68(6):394-424.

[4] Rakha EA, Reis-Filho JS, Baehner F, et al. Breast cancer prognostic classification in the molecular era: the role of histological grade. Breast Cancer Res 2010;12(4):207.

[5] Bloom H, Richardson W. Histological grading and prognosis in breast cancer; a study of 1409 cases of which 359 have been followed for 15 years. Br J Cancer 1957;11(3):359-77.

[6] Brant MK, Hansen DM. California cancer reporting system standards volume I. 18 th edn Version 1.2, December 2019.

[7] Kondov B, Milenkovikj Z, Kondov G, et al. Presentation of the molecular subtypes of breast cancer detected by immunohistochemistry in surgically treated patients. Open Access Maced J Med Sci 2018;6(6):961-7.

[8] Hu H, Liu YH, Xu L, et al. Clinicopathological classification and individualized treatment of breast cancer. Chinese Med J (Engl) 2013;126(20):3921-5.

[9] Goldhirsch A, Winer EP, Coates AS, et al. Personalizing the treatment of women with early breast cancer: highlights of the St Gallen International Expert Consensus on the Primary Therapy of Early Breast Cancer 2013. Ann Oncol 2013;24(9):2206-23.

[10] Yadav R, Sen R, Chauhan P. Role of cytokeratin biomarkers in breast carcinoma. Asian Journal of Pharmaceutical and Clinical Research 2016;9(6):293-6.

[11] van Diest PJ, van der Wall E, Baak JPA. Prognostic value of proliferation in invasive breast cancer: a review. J Clin Pathol 2004;57(7):675-81.

[12]Ajura AJ, Sumairi I, Lau SH. The use of immunohistochemistry in an oral pathology laboratory. Malays J Pathol 2007;29(2):101-5. 
[13] Zaha DC. Significance of immunohistochemistry in breast cancer. World J Clin Oncol 2014;5(3):382-92.

[14] Taneja P, Maglic D, Kai F, et al. Classical and novel prognostic markers of breast cancer and their clinical significance. Clin Med Insights Oncol 2010;4:15-34.

[15] Rekhtman N, Bishop JA. Quick reference handbook for surgical pathologists. Berlin Heidelberg: Springer-Verlag 2011: p. 44.

[16] Shao MM, Chan SK, Yu AMC, et al. Keratin expression in breast cancers. Virchows Arch 2012;461(3):313-22.

[17] Choccalingam C, Rao L, Rao S. Clinico-pathological characteristics of triple negative and non triple negative high grade breast carcinomas with and without basal marker (CK5/6 and EGFR) expression at a rural tertiary hospital in India. Breast Cancer 2012;6:21-9.

[18] Aiad HA, Samaka RM, Asaad NY, et al. Relationship of CK8/18 expression pattern to breast cancer immunohistochemical subtyping in Egyptian patients. Ecancermedicalscience 2014;8:404.

[19] Moll R, Divo M, Langbein L. The human keratins: biology and pathology. Histochem Cell Biol 2008;129(6):705-33.

[20] Lehr HA, Folpe A, Yaziji H, et al. Cytokeratin 8 immunostaining pattern and E-cadherin expression distinguish lobular from ductal breast carcinoma. Am J Clin Pathol 2000;114(2):190-6.

[21] Kongara S, Kravchuk O, Teplova I et al. Autophagy regulates keratin 8 homeostasis in mammary epithelial cells and in breast tumours. Mol Cancer Res 2010;8(6):873-84.

[22] John RG. Breast. In: Rosai J, ed. Rosai and Ackerman's surgical pathology. 10th edn. Vol. 2. Mosby Elsevier 2011:1686-8.
[23] El-Rehim DMA, Pinder SE, Paish CE, et al. Expression of luminal and basal cytokeratins in human breast carcinoma. J Pathol 2004;203(2):661-71.

[24] Alshareeda AT, Soria D, Garibaldi JM, et al. Characteristics of basal cytokeratin expression in breast cancer. Breast Cancer Res Treat 2013;139(1):23-37.

[25] Dogu GG, Ozkan M, Ozturk F, et al. Triple-negative breast cancer: immunohistochemical correlation with basaloid markers and prognostic value of survivin. Med Oncol 2010;27(1):34-9.

[26] Livasy CA, Karaca G, Nanda R, et al. Phenotypic evaluation of the basal-like subtype of invasive breast carcinoma. Mod Pathol 2006;19(2):264-71.

[27] Laakso M, Loman N, Borg A, et al. Cytokeratin 5/14positive breast cancer: true basal phenotype confined to BRCA1 tumours. Modern Pathology 2005;18(10):1321-8.

[28] Schaller G, Fuchs I, Pritze W, et al. Elevated keratin 18 protein expression indicates a favorable prognosis in patients with breast cancer. Clin Cancer Res 1996;2(11):1879-85.

[29] Hashmi AA, Naz S, Hashmi SK, et al. Cytokeratin 5/6 and cytokeratin 8/18 expression in triple negative breast cancers: clinicopathologic significance in South-Asian population. BMC Research Notes 2018;11(1):372.

[30] Becker M, Nitsche A, Neumann C, et al. Sensitive PCR method for the detection and real-time quantification of human cells in xenotransplantation systems. Br J Cancer 2002;87(11):1328-35.

[31] Chu P, Wu E, Weiss LM. Cytokeratin 7 and cytokeratin 20 expression in epithelial neoplasms: a survey of 435 cases. Mod Pathol 2000;13(9):962-72. 